\title{
SEISMIC BEARING CAPACITY OF PILES IN LIQUEFIABLE SOILS
}

\author{
J. A. KNAPPETT ${ }^{\mathrm{i})}$ and S. P. G. MADABHUSH ${ }^{\mathrm{ii}}$
}

\begin{abstract}
An investigation into the base capacity of piles in passing through loose, liquefiable sand and founded in underlying dense sand is presented based on the results of a series of dynamic centrifuge tests on instrumented model pile groups. Excess pore pressures equal in magnitude to the initial effective vertical stress were observed to be generated in the bearing layer of dense sand at both shallow $(15 \mathrm{~m})$ and deep $(26 \mathrm{~m})$ depths. This induced a dramatic reduction in base capacity and consequently, large settlements of the piles by as much as $\sim 5 D_{0}$. A spherical cavity expansion solution for base capacity was validated against measured values showing good agreement, provided that excess pore pressure and dynamic shear stiffness in the bearing layer are known. A simple closed-form relationship, applicable to end-bearing piles, between the degree of liquefaction and the initial pile static safety factor was then developed against plunging failure at the pile base which can be used in design.
\end{abstract}

Key words: bearing capacity, centrifuge model test, liquefaction, piles, seismic design, settlement (IGC: D7/E4/E8)

\section{INTRODUCTION}

Displacement of piled foundations during liquefaction has been a major cause of structural collapse during earthquake shaking in recent years (Tokimatsu et al., 1996; Tokimatsu and Asaka, 1998; Tokimatsu et al., 1998; Lin et al., 2005). While it is commonly accepted that lateral displacements can be severely damaging, little attention has been paid to vertical settlement which can similarly lead to structural damage (Zhang and $\mathrm{Ng}$, 2005), despite the fact that this governs the design of piles under conventional static conditions. The onset of significant and damaging pile settlement with liquefaction during earthquake shaking has already been established (De Alba, 1983; Knappett, 2006) and empirical relationships between the severity of liquefaction and pile group settlement have been developed (Knappett and Madabhushi, 2008a). However, in order to develop more deterministic methods of predicting the onset of damaging pile settlement, further investigation is needed to measure the loads carried by piles-both at the pile base and along the shaft-when the soil around them liquefies. This paper aims to address this issue by presenting recently collected dynamic centrifuge test results and using these to develop simple methods of predicting the changes in pile base bearing capacity.

Comparison of these model testing studies with recent field testing work (Rollins and Strand, 2006) has demonstrated the importance of the behaviour of the more competent underlying bearing layers into which the piles are installed. In this latter work, controlled blasting was used to generate liquefaction in a $\sim 10 \mathrm{~m}$ thick sand layer which the piles passed through, but not in the bearing layer. This condition is somewhat artificial as in real earthquakes, it is upward-propagating shear waves from deep layers (bedrock) that generate excess pore pressures. These waves pass through the 'competent' bearing layers and may therefore lead to substantial increases in excess pore pressure there. Co-seismic settlements were found to be small in the field tests, while in the model tests presented by De Alba (1983) in which the underlying soil suffers a substantial increase in excess pore pressure, settlements approaching twice the pile diameter were measured. It is already well established that dense sands may develop significant excess pore pressures during undrained cyclic loading (Mitchell and Dubin, 1986) up to $\Delta u / \sigma_{\mathrm{v} 0}^{\prime} \approx 1$. However on shearing, strong dilation occurs such that the sand has a limited strain potential, unlike liquefied loose sands. This condition is called cyclic mobility (Castro, 1975; Castro and Poulos, 1977). Further to this, Steedman and Sharp (2001) conducted a centrifuge modelling study on the excess pore pressures developed in mediumdense saturated sands at high initial effective stress. The results suggested that for $\sigma_{v 0}^{\prime}>200 \mathrm{kPa}$, the maximum value of the liquefaction ratio which could be achieved reduced by approximately $15 \%$ for each increase of $\sigma_{\mathrm{v} 0}^{\prime}$ by $200 \mathrm{kPa}$. This may have important implications for the liquefied bearing capacity of deep/long pile founded in dense sand. It is therefore important to additionally confirm whether competent bearing layers suffer substantial

i) Lecturer, University of Dundee, Division of Civil Engineering, Scotland, UK (j.a.knappett@dundee.ac.uk) (formerly University of Cambridge, UK).

ii) Reader, University of Cambridge, Department of Engineering, UK.

The manuscript for this paper was received for review on March 26, 2007; approved on June 8, 2009.

Written discussions on this paper should be submitted before March 1, 2010 to the Japanese Geotechnical Society, 4-38-2, Sengoku, Bunkyoku, Tokyo 112-0011, Japan. Upon request the closing date may be extended one month. 


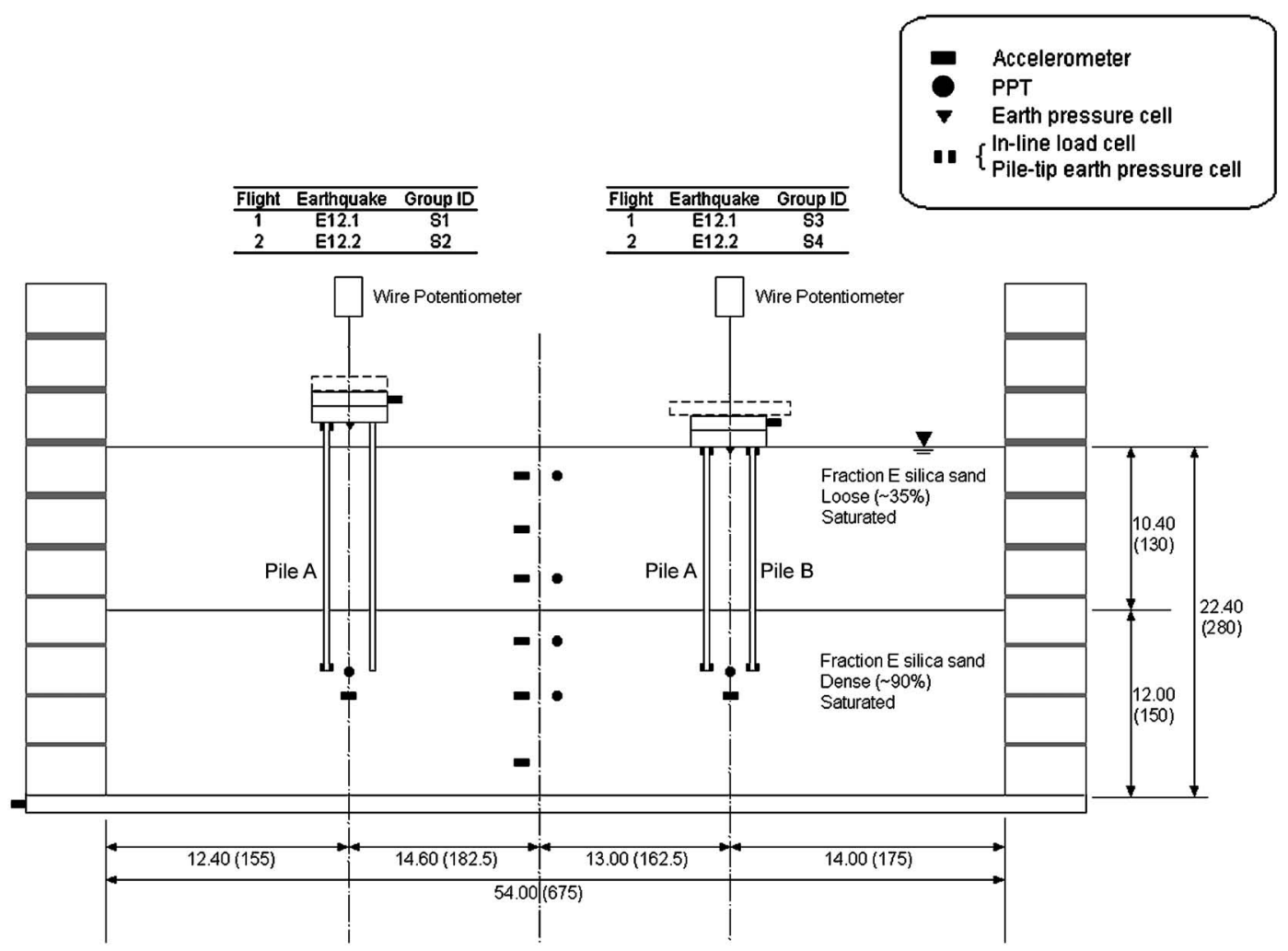

Fig. 1. Schematic layout of test, JK-12, dimensions in $\mathrm{m}$ at prototype scale (mm model scale)

increases in excess pore pressure which may cause a dramatic drop in bearing capacity and increased settlement when disturbed by upwards-propagating shear waves.

\section{DYNAMIC CENTRIFUGE MODELLING}

Two different soil profiles were used in the series of centrifuge tests presented herein, which were conducted at 80 -g. The first, with test ID JK-12, consisted of a $10.4 \mathrm{~m}$ deep layer of loose $\left(D_{\mathrm{r}} \approx 35 \%\right)$ Fraction E silica sand, overlying a much denser layer of the same sand $\left(D_{\mathrm{r}} \approx\right.$ $85 \%$ ). The thickness of this layer and all other values in this paper are given at prototype scale. This soil profile was prepared in a deep equivalent shear beam (ESB) container to reduce reflections of shear waves at the soil boundaries. Further details concerning the design and performance of this container can be found in Brennan (2003) and Brennan et al. (2006). The soil layers were instrumented with accelerometers and pore pressure transducers to determine the free-field soil response as shown in Fig. 1 and the model saturated with a solution of Methylcellulose and water of viscosity $80 \mathrm{cS}$ such that the permeability of the soil is correctly scaled (Schofield, 1981; Madabhushi, 1994). Further information regarding the use of Methylcellulose as a model pore fluid may be found in Stewart et al. (1998).

Two axially-loaded $2 \times 2$ pile groups with a pile-to-pile spacing of $s=5.6 D_{0}$ were installed into these layers, initially under 1-g conditions and subsequently under increasing self-weight during swing-up of the centrifuge. The piles were nominally models of $0.5 \mathrm{~m}$ diameter $\left(D_{0}\right)$ steel tubular piles with closed ends, having a bending stiffness $E I=164 \mathrm{MNm}^{2}$ (determined from four-point bending tests) and an axial compressive stiffness of $E A$ / $L_{\mathrm{p}}=0.96 \mathrm{MNm}^{-1}$. One of the pile groups was installed such that the pile cap was clear of the surface of the sand to observe the behaviour of the piles alone, while the other was installed such that the pile cap was in contact with the sand which is a more common condition for piled foundations in the field. Three of the model piles were instrumented, having a sub-miniature total earth pressure cell installed into the tip with a sensing area equal to the pile base area, and a miniature tension-compression load cell installed at the pile head. By measuring pile base load $\left(Q_{\mathrm{b}}\right)$ and total pile load $(P)$ in this way, it was also possible to determine the total shaft load $\left(Q_{s}\right)$ by subtraction. Two of these instrumented piles were installed in identical locations in the two pile groups (pile A-see Fig. 1), while the third was installed into the group with the pile cap contacting the sand to measure any frame effect and transfer of load between the piles which might occur during shaking (pile B-see Fig. 1). Bearing pressures beneath the centreline of the pile caps were also measured in both cases using surface-mount earth pressure cells and settlements of the pile groups were measured using wire potentiometers mounted to an overhead gantry.

The second soil profile (which was actually tested first) was denoted JK-06 and represented a much deeper deposit of loose sand $21.6 \mathrm{~m}$ deep, again overlying a more competent bearing layer. This is shown schematically in Fig. 2. The model preparation and densities of the sand 


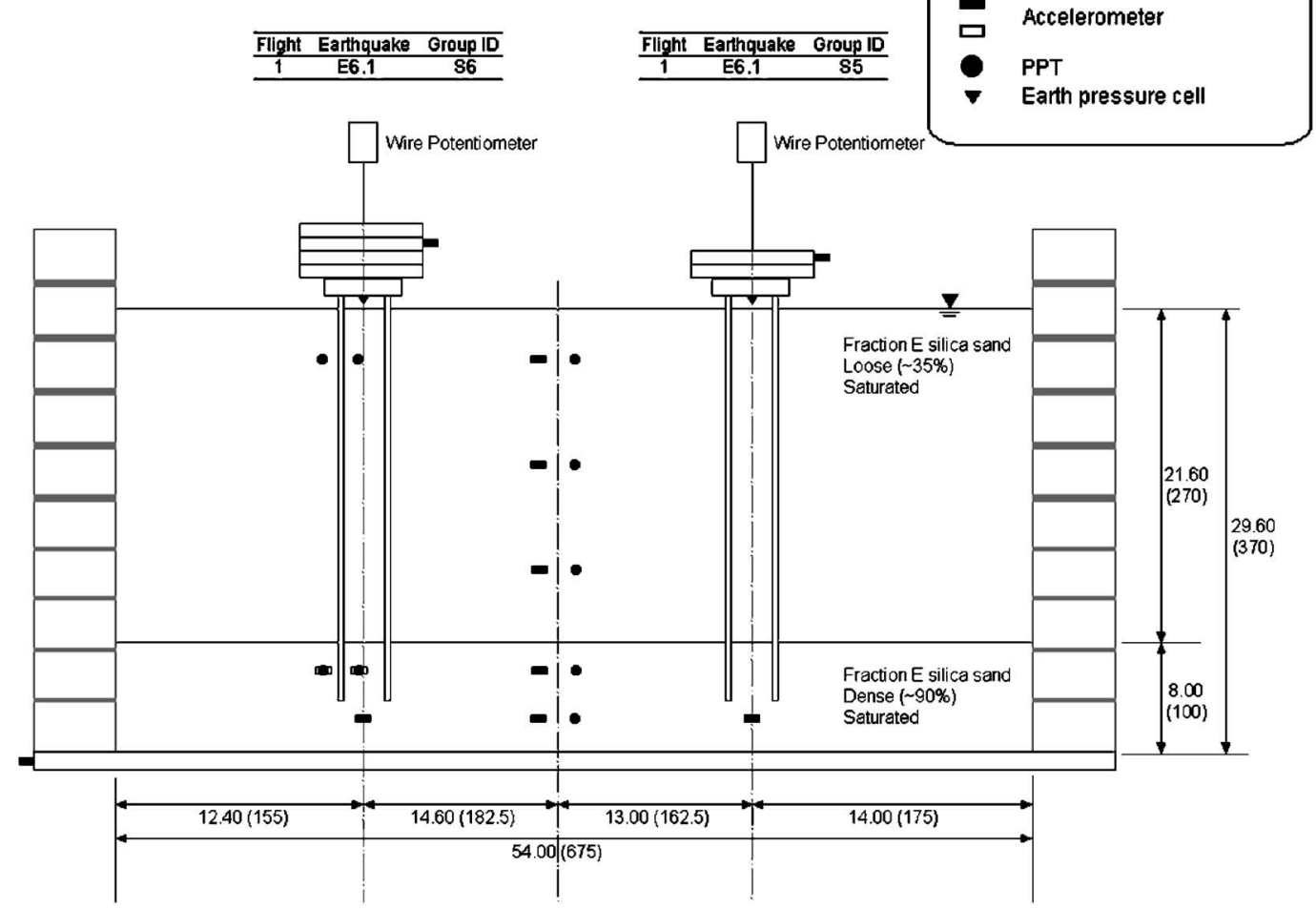

Fig. 2. Schematic layout of test, JK-06, dimensions in $\mathbf{m}$ at prototype scale (mm model scale)

Table 1. Static properties of tested pile groups

\begin{tabular}{|c|c|c|c|c|c|c|c|c|}
\hline Test ID & Earthquake ID & Group ID & $P(\mathrm{MN})$ & $Q_{\mathrm{b} 0, \text { ult }}^{1}(\mathrm{MN})$ & $K^{2}$ & $Q_{\mathrm{s} 0, \mathrm{ult}^{2}}(\mathrm{MN})$ & $\mathrm{SSF}^{*}$ & Pile cap-soil contact? \\
\hline \multirow{4}{*}{$\mathrm{JK}-12$} & 12.1 & $\mathrm{~S} 1$ & 0.45 & 2.44 & 0.66 & 0.317 & $6.13(3.42)$ & No \\
\hline & 12.2 & $\mathrm{~S} 2$ & 0.65 & 2.58 & 0.74 & 0.351 & $4.51(2.52)$ & No \\
\hline & 12.1 & $\mathrm{~S} 3$ & 0.45 & 2.44 & 0.66 & 0.317 & $6.13(3.42)$ & Yes \\
\hline & 12.2 & S4 & 1.25 & 2.44 & 0.74 & 0.351 & $2.24(1.26)$ & Yes \\
\hline \multirow{2}{*}{ JK-06 } & 6.1 & S5 & 1.88 & 3.39 & 0.66 & 0.952 & $2.32(1.41)$ & No \\
\hline & 6.1 & S6 & 3.45 & 3.39 & 0.66 & 0.952 & $1.26(0.77)$ & No \\
\hline
\end{tabular}

${ }^{1}$ Calculated following the method of Berezantzev et al. (1961) as modified by Cheng (2004)

${ }^{2}$ Values of $K$ and $Q_{\text {s0 }}$, ult calculated as described in the text

* Revised values in parentheses are based on back-calculated estimates of static base capacity

layers were identical to those used in test JK-12. Similar 2 $\times 2$ pile groups were installed as shown in Fig. 2, though the piles were longer such that the embedded length in the dense sand layer remained the same as that tested in JK-12, with this length being $\sim 10 D_{0}$. The piles in this test were not instrumented and each group was installed with the pile cap clear of the surface of the loose sand layer.

A summary of the static configurations of the tested pile groups is given in Table 1. Static base capacity $\left(Q_{\mathrm{b} 0 \text {, ult }}\right)$ was initially calculated using the analysis of Berezantzev et al. (1961) as modified by Cheng (2004). Shaft capacity was estimated based on back-calculated values of the coefficient of lateral earth pressure which were obtained using measured pile shaft loads during swing-up of the centrifuge for pile groups S1 and S2 (which have no effect of the pile cap). These values of $K$ were found to be between 0.66-0.74. Assuming that $K_{0}=$ $1-\sin \phi=0.45$ gives $K \approx 1.5 K_{0}$ such that the piles are broadly representative of driven piles in the field (Kulhawy, 1984). This information was then used to compute shaft capacity for the pile groups in this study using

$$
Q_{\mathrm{s} 0, \mathrm{ult}}=\left(\pi D_{0} L_{\mathrm{p}}\right) \cdot \mu \cdot K \bar{\sigma}_{\mathrm{v} 0}^{\prime}
$$

where $\bar{\sigma}_{\mathrm{v} 0}^{\prime}$ is the average vertical effective stress over the length of the pile $\left(L_{\mathrm{p}}\right)$ and $\mu$ is the coefficient of friction at the sand-pile interface, assumed to be 0.3 for smooth piles following the recommendations of Uesugi and Kishida (1986). Further details regarding the computation of static pile capacities can be found in Knappett (2006). 
Table 2. Summary of simulated earthquakes

\begin{tabular}{c|c|c}
\hline Test ID & Earthquake ID & Peak bedrock acceleration $(g)$ \\
\hline JK-06 & 6.1 & 0.25 \\
\hline \multirow{2}{*}{ JK-12 } & 12.1 & 0.31 \\
\cline { 2 - 3 } & 12.2 & 0.30 \\
\hline
\end{tabular}

Axial loading was applied to the piles by a combination of the mass of the pile cap, and a series of brass and aluminium plates which were bolted to the upper surface of the pile cap. It should be noted that the superstructural weight which is modelled by these plates was unable to move. In reality, the centre-of-mass of the supported structure would move horizontally relative to the pile cap, which would impart an additional dynamic overturning moment to the pile cap which is not modelled in these tests. This will serve to increase the cyclic axial loads which are transferred to the piles during the earthquakes such that the settlements presented herein are likely to be a lower-bound to the true behaviour. Further research would be necessary to quantify this effect for different types of superstructure.

Static safety factors (SSFs) were then calculated as the total pile capacity $\left(=Q_{\mathrm{b} 0 \text {,ult }}+Q_{\mathrm{s} 0 \text {,ult }}\right)$ divided by the applied pile head load. The total supported dead load from the pile cap and additional plates was assumed to be supported equally across the four piles in the group for the purposes of calculating a nominal SSF for the piles. By interpolating the post-liquefaction bearing capacities observed during the simulated earthquakes to the static case, back-calculated static base capacities were compared to the initial predicted values which were found to be too high by a factor of approximately two. Revised static safety factors (SSFs) using the back-calculated values are shown in parentheses in Table 1 .

Each soil model was subjected to sinusoidal strong shaking for $48 \mathrm{~s}$ at a fundamental frequency of $0.63 \mathrm{~Hz}$ (both parameters at prototype scale). This was simulated using the stored angular momentum (SAM) earthquake actuator, the performance and construction of which are detailed by Madabhushi et al. (1998). A single earthquake was applied during test $\mathrm{JK}-06$, while in JK-12, additional load was added to the pile groups following the initial event, with the model then being reflown and subjected to a second earthquake of similar magnitude. Peak ground acceleration measured at the base of the container (equivalent bedrock layer) was used to quantify the magnitude of shaking, the values of which are given in Table 2.

\section{OBSERVED LIQUEFACTION BEHAVIOUR}

The excess pore pressures developed in the free-field in both the shallow (JK-12) and deep (JK-06) soil profiles tested are shown in Figs. 3 and 4 respectively. It will be seen from these two figures that full liquefaction, defined here as $\Delta u / \sigma_{\mathrm{v} 0}^{\prime}=1$, is achieved at all measured depths in
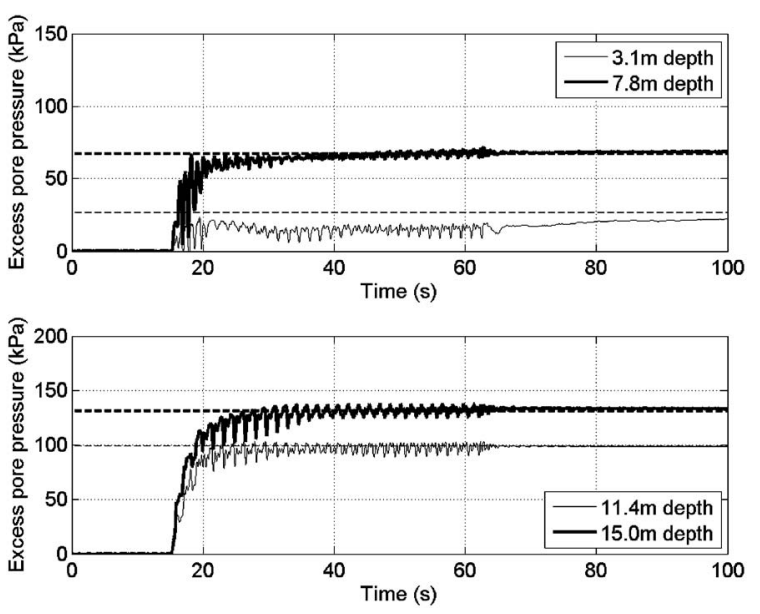

Fig. 3. Excess pore pressures measured in Earthquake 12.1
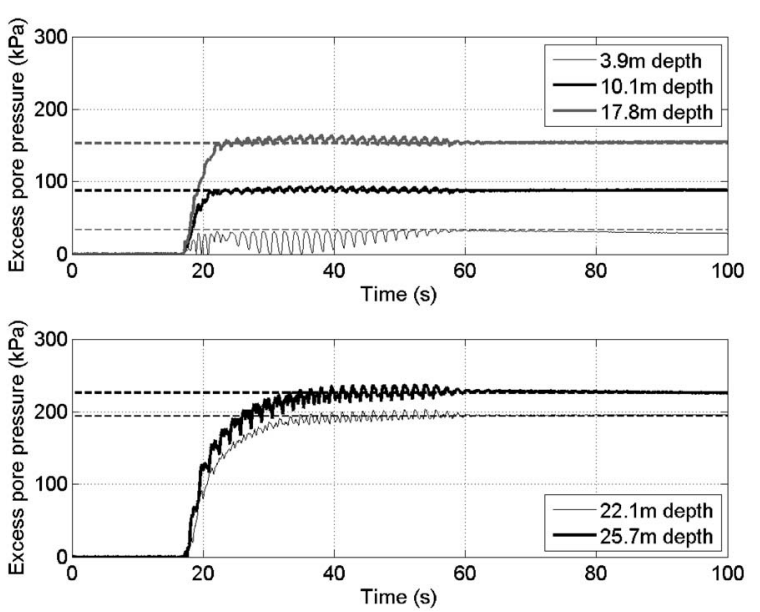

Fig. 4. Excess pore pressures measured in Earthquake 6.1

both of the earthquakes shown. Similar time histories of excess pore pressure were observed in earthquake 12.2 which is not shown graphically.

In the work reported by Steedman and Sharp (2001) excess pore pressures achieved at an initial vertical effective stress of $\sim 250 \mathrm{kPa}$ ( $\sim 25 \mathrm{~m}$ deep) were only $60-80 \%$ of the full liquefaction values achieved in the denser sand used in the tests presented herein. This is detailed in Table 3. The results presented in Fig. 4 have shown that full liquefaction $\left(\Delta u / \sigma_{\mathrm{v} 0}^{\prime}=1\right)$ is possible even in deep, dense sand strata. These high excess pore pressures will lead to lower effective stresses and hence, bearing capacity in such layers would be expected to be reduced. This has important implications for the settlement behaviour of endbearing piled foundations as even deep piles founded in dense sand may suffer a significant loss of end-bearing capacity and excessive settlement.

\section{Liquefaction-induced Settlement}

The settlements of the pile groups in which there was no contact between the pile cap and the soil are summarised in Table 3 and qualitatively compared to the full- 
Table 3. Influence of excess pore pressure generation on liquefaction-induced settlement (no effect of pile cap bearing)

\begin{tabular}{|c|c|c|c|c|c|}
\hline \multirow{2}{*}{ Group/pile ID } & \multicolumn{2}{|c|}{ At pile tip level } & \multirow{2}{*}{$\begin{array}{c}\text { Range of } \Delta u / \sigma_{\mathrm{v} 0}^{\prime} \text { after } \\
\text { Steedman and Sharp (2001) }\end{array}$} & \multicolumn{2}{|c|}{ Settlement (mm) } \\
\hline & Depth (m) & $\Delta u / \sigma_{\mathrm{v} 0}^{\prime}$ & & Co-seismic & Post-shaking \\
\hline S1 & 15.2 & 1.00 & $0.7-1.0$ & 1137 & 317 \\
\hline S2 & 15.2 & 0.96 & $0.7-1.0$ & 635 & 14 \\
\hline S5 & 26.4 & 1.00 & $0.6-0.8$ & 1480 & 88 \\
\hline S6 & 26.4 & 1.00 & $0.6-0.8$ & 2342 & 144 \\
\hline Rollins and Strand (2006) & 21.3 & $<0.2$ & - & & \\
\hline
\end{tabular}

scale test results of Rollins and Strand (2006) which likewise exclude the contribution of the pile cap to the load carrying capacity of the foundation. It is immediately obvious from Table 3 that the excess pore pressure developed in the bearing layer at pile tip level has a controlling effect on settlement. If full liquefaction occurs (groups S1-S6) co-seismic liquefaction-induced settlements were observed to be greater than one pile diameter in all cases and as large as $\sim 5 D_{0}$, while for $\Delta u / \sigma_{\mathrm{v} 0}^{\prime}<0.2$ in sand of lower density $\left(D_{\mathrm{r}} \approx 50 \%\right)$ from the full-scale tests, hardly any pile settlement occurred at all. It is also clear from Table 3 that if high excess pore pressures are generated at pile tip level, the resulting co-seismic settlement is very much larger than any settlement which occurs post-earthquake. Post-earthquake settlement occurs as the sand reconsolidates during the dissipation of excess pore pressures. This reconsolidation generates additional downwards shear stress along the pile shaft, which is commonly termed downdrag. For piles founded in non-liquefying bearing layers, downdrag-induced settlements may form an appreciable component of the total (albeit small) settlements that occur (Rollins and Strand, 2006). For the cases tested herein however, post-earthquake settlement is small compared to the co-seismic settlement and as such, only the behaviour and capacity of the piles during the earthquake will be considered in the remainder of this paper.

\section{MEASURED PILE LOADS IN LIQUEFIED SOIL}

The load components measured in the instrumented piles in groups S3 and S1 (pile A for both) are shown in Fig. 5. It is immediately obvious from Fig. 5 that for group S3, the load carried at the base of the piles $\left(Q_{\mathrm{bE}}\right)$ reduces with time corresponding to increasing excess pore pressure at pile tip level (see Fig. 3). As the piles are settling during this reduction in base load, as evidenced by the increasing overall pile group settlement $\left(\rho_{\mathrm{E}, \text { avg }}\right)$, the drop in the carried load can only be explained by a drop in bearing capacity. It is also clear from Fig. 5, however that the base load for group S1 increased during shaking. This may be attributed to the reductions in excess pore pressure beneath the pile tip which occur with shearing of the soil in this region due to the much higher rate of settlement in this group, itself a result of the lack of any resistance to settlement from the pile cap in this case.
Figure 6 summarises the shaft and base loads in the instrumented piles at the time instants shown in the figure. With the exception of pile A in group S1, all of the piles in Fig. 6 show a reduction in base load due to shaking and the consequent liquefaction which occurs. Regarding shaft loads, it is obvious from Fig. 5 that shaft capacity does not reduce to zero with liquefaction of the soil as has previously been assumed in various analytical studies (e.g., Boulanger et al., 2003; Haldar et al., 2007).

Superimposed on these average behaviours is a substantial cyclic load component as the pile group rocks under the action of the inertial load which causes the piles to move cyclically up and down. The cyclic vertical movement of the instrumented piles shown in Fig. 5 as $\rho_{\mathrm{E}, \mathrm{cyc}}$ was estimated by assuming that the piles and cap rock as a rigid body about a point beneath the centreline of the foundation at pile tip level. Horizontal cyclic displacements $\left(\Delta_{\text {cyc }}\right)$, which were computed by carefully integrating measured pile cap accelerations, are then related to the estimated cyclic vertical movement according to

$$
\rho_{\mathrm{E}, \mathrm{cyc}}=\frac{s}{2} \tan \left(\frac{\Delta_{\mathrm{cyc}}}{L_{\mathrm{p}}+h_{\mathrm{CM}}}\right)
$$

where $s$ is the pile spacing $\left(=5.6 D_{0}\right.$ for all tests presented herein), and $h_{\mathrm{CM}}$ is the distance from the pile-cap-soil interface to the centreline of the accelerometers used to measure the pile cap lateral movement. In the absence of any effect of the pile cap (i.e., group S1) it is clear from Fig. 5 that the cyclic lateral displacements of the piles are increased. This correlates with larger cyclic shaft load variations compared with those observed in group S3.

The final point of note concerning Fig. 5 is that when the pile cap is in contact with the surface of the liquefied sand for group S3 (and S4, which is not shown) there is a substantial increase of pile cap bearing pressure $\Delta q_{\text {cap }}$ with increasing settlement. The overall group settlement is also smaller for group S3 than for group S1 in which there is no contribution from the cap. The pile cap therefore appears to play an important role in resisting settlement by generating additional bearing pressure in the liquefied sand on which it sits; however, this effect will not be discussed further in this paper which concentrates on pile capacity. A more detailed discussion of the effect of the pile cap in resisting settlement may be found in Knappett and Madabhushi (2008a).

In addition to showing changes in pile load distribution 

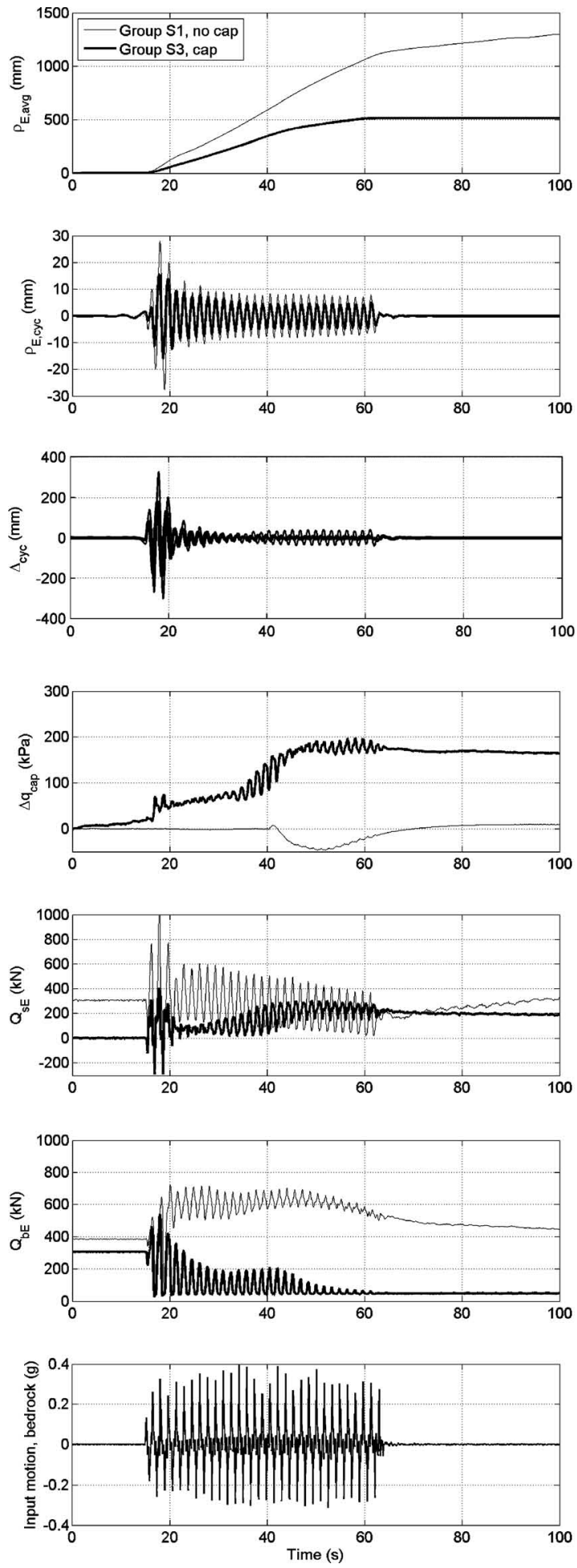

Fig. 5. Effect of pile cap on load transfer during liquefaction (pile $A$, Earthquake 12.1)

between shaft and base due to liquefaction, Fig. 6 also demonstrates that following liquefaction, the pile does not return to its initial distribution of base and shaft load. This has potential implications for the assessment of piled foundations following earthquakes (i.e., for the purposes of making future design changes to the supported superstructure) and for determining behaviour in subsequent earthquakes (including aftershocks). The distri- bution of shaft and base load may be determined by considering the proportion of the total pile load carried by the base $(\alpha)$

$$
\alpha=\frac{Q_{\mathrm{b} 0}}{P} .
$$

High values of $\alpha$ indicate that the piles carry most of the load in end-bearing, while low values of $\alpha$ suggest conditions closer to friction piles. Values of $\alpha$ have been computed for all six instrumented piles, both for pre-earthquake conditions and following dissipation of excess pore pressures, using the load components shown in Fig. 6. These values are compared in Fig. 7. It is immediately obvious from Fig. 7 that all of the instrumented piles may be considered as end-bearing, carrying more than half of the total pile load at the pile base. In all cases, the load distribution can be seen to change. Based on the data presented here, it appears that the change in load distribution depends on whether the pile cap contributes to the overall bearing capacity. For cases in which there is no effect of the pile cap, load is effectively transferred from the shaft to the base as a result of the earthquake. For cases in which the pile cap does contribute to the bearing capacity, load is transferred from the base to the shaft of the piles.

Figure 7 additionally shows the approximate distribution of load between the piles and the pile cap for the instrumented pile tests. This is defined in terms of a parameter $\beta$ given by

$$
\beta=\frac{4 P}{P_{\mathrm{t}}}
$$

where $P_{\mathrm{t}}$ is the total superstructural load supported by the foundation. The average pile load $P$ in Eq. (4) was determined by taking the average value of the total pile head loads measured in piles A and B in each group. Figure 7 shows that there is comparatively little change in the distribution of load between the piles and pile cap following liquefaction.

\section{LIQUEFIED PILE BASE CAPACITY $\left(Q_{\mathrm{bE}, \mathrm{ult}}\right)$}

For end-bearing piles, the pile base capacity represents the largest individual component of load contributing to the overall bearing capacity of the foundation. As a result of this, in order to be able to determine a suitable axial pile load to avoid bearing capacity failure, it will be most important to be able to predict the reduction in bearing capacity at the pile base. The high excess pore pressures which are developed in the bearing layer at pile tip level lead to a substantial reduction in shear modulus. This parameter may be obtained from measurements of cyclic shear stress and shear strain inferred from accelerometer measurements as detailed by Brennan et al. (2005). Stress-strain loops obtained in this way can be used to determine a representative secant shear modulus for each individual cycle of the earthquake. Average values of secant shear modulus for the soil between the pile base and the base of the container (equivalent bedrock level) 


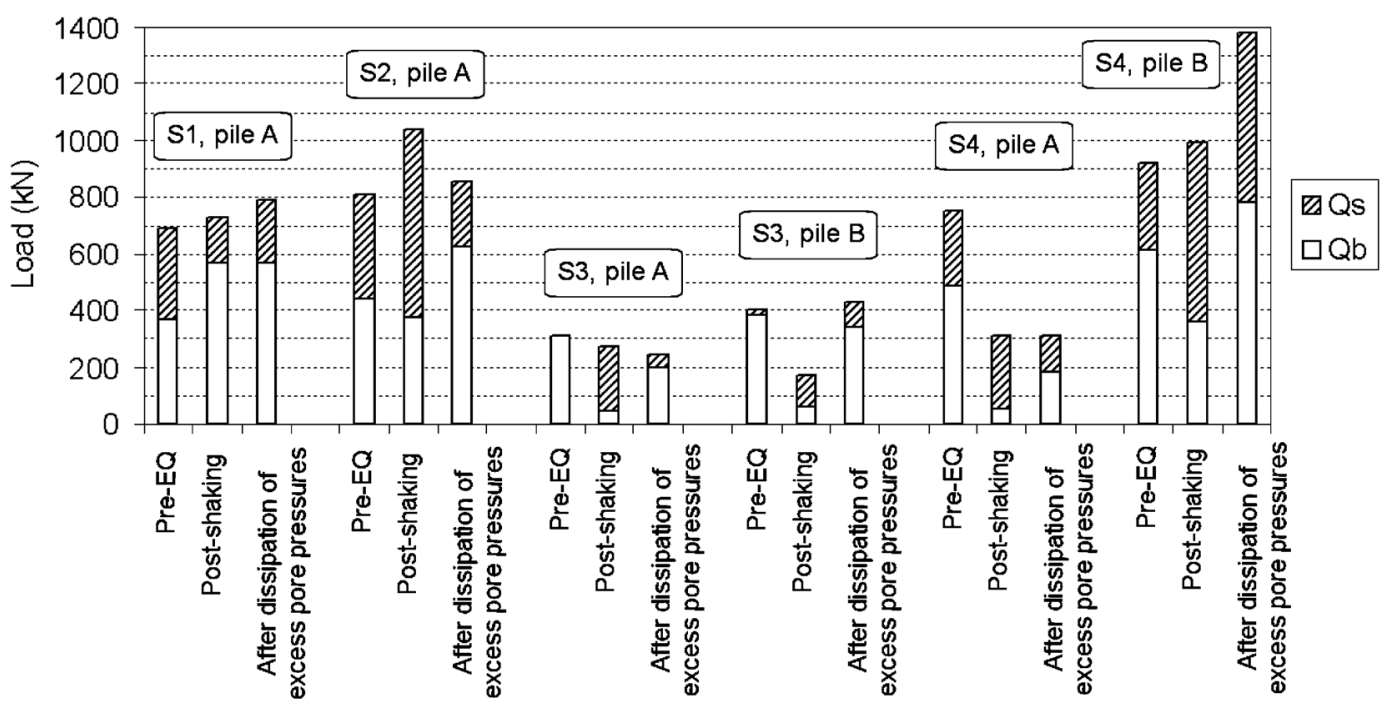

Fig. 6. Summary of changes in pile loads, groups with pile cap contact
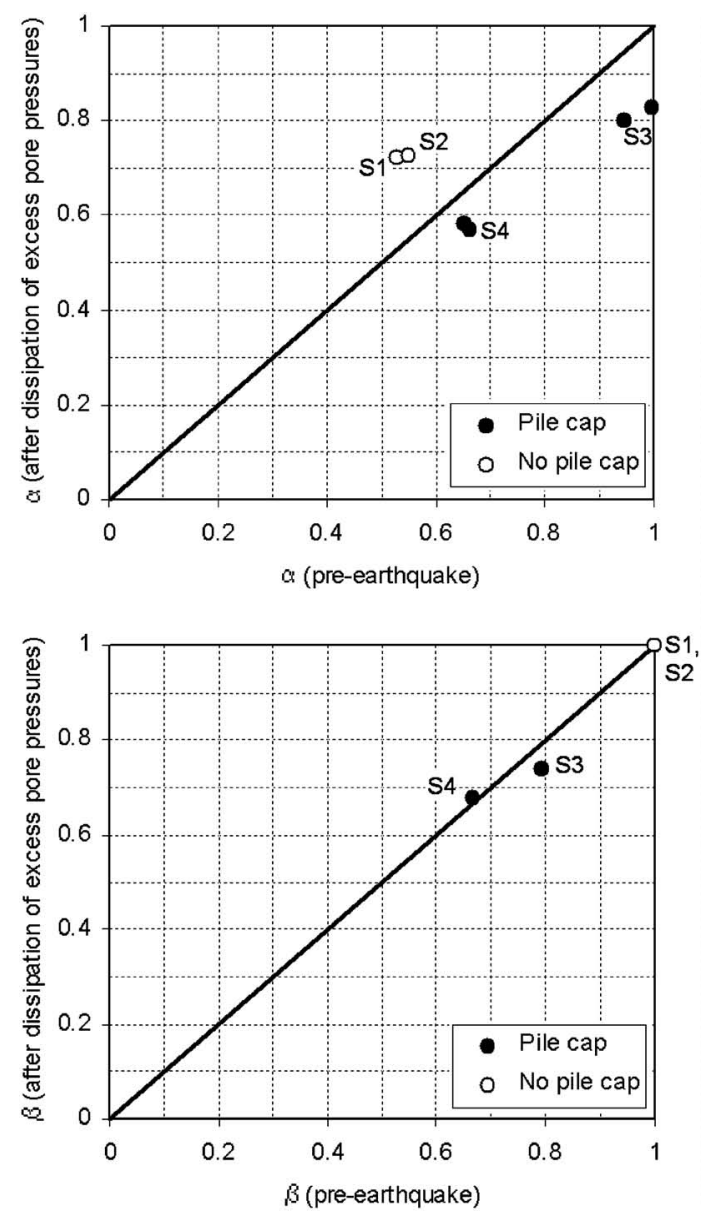

Fig. 7. Change in static pile load distribution due to liquefaction

both beneath the pile groups and in the free field in both tests JK-12 and JK-06 are shown in Fig. 8. These were determined based on a first-order estimate of shear stresses and strains using the input accelerometer and the accelerometers at each location at pile tip level.

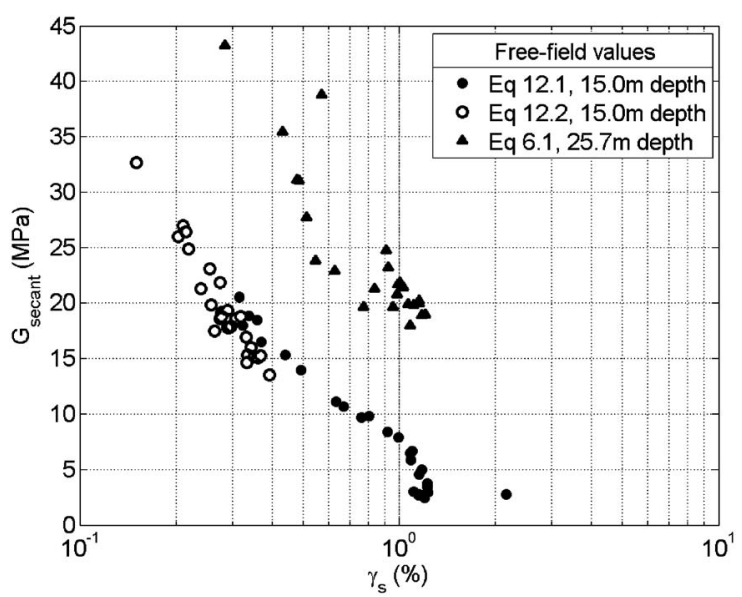

Fig. 8. Measured dynamic shear moduli

The free-field values in Fig. 8 show that the sand in both earthquakes 12.1 and 12.2 follows the same $G-\gamma_{\text {s }}$ relationship, though the strains mobilised during the second of the two earthquakes are much lower than those in the first earthquake. This is thought to be due to densification of the sand during the initial earthquake which reduces the potential for the soil to strain under subsequent excitation. Comparison of the two first-earthquake conditions (earthquakes 6.1 and 12.1) show a similar range of strain mobilisation, though the magnitude of the shear modulus is higher at greater depth for test JK-06 (earthquake 6.1).

The measured values of effective stress and shear modulus from the centrifuge tests have been incorporated into a modified form of the spherical cavity expansion model for pile base capacity originally proposed by Vesic (1972) and later modified by Yasufuku et al. (2001). The method is modified to account for the time varying parameters ( $\sigma_{\mathrm{v}}^{\prime}$ and $G_{\text {secant }}$ ) and the volumetric compression is taken to be zero (i.e., assuming that the expansion 

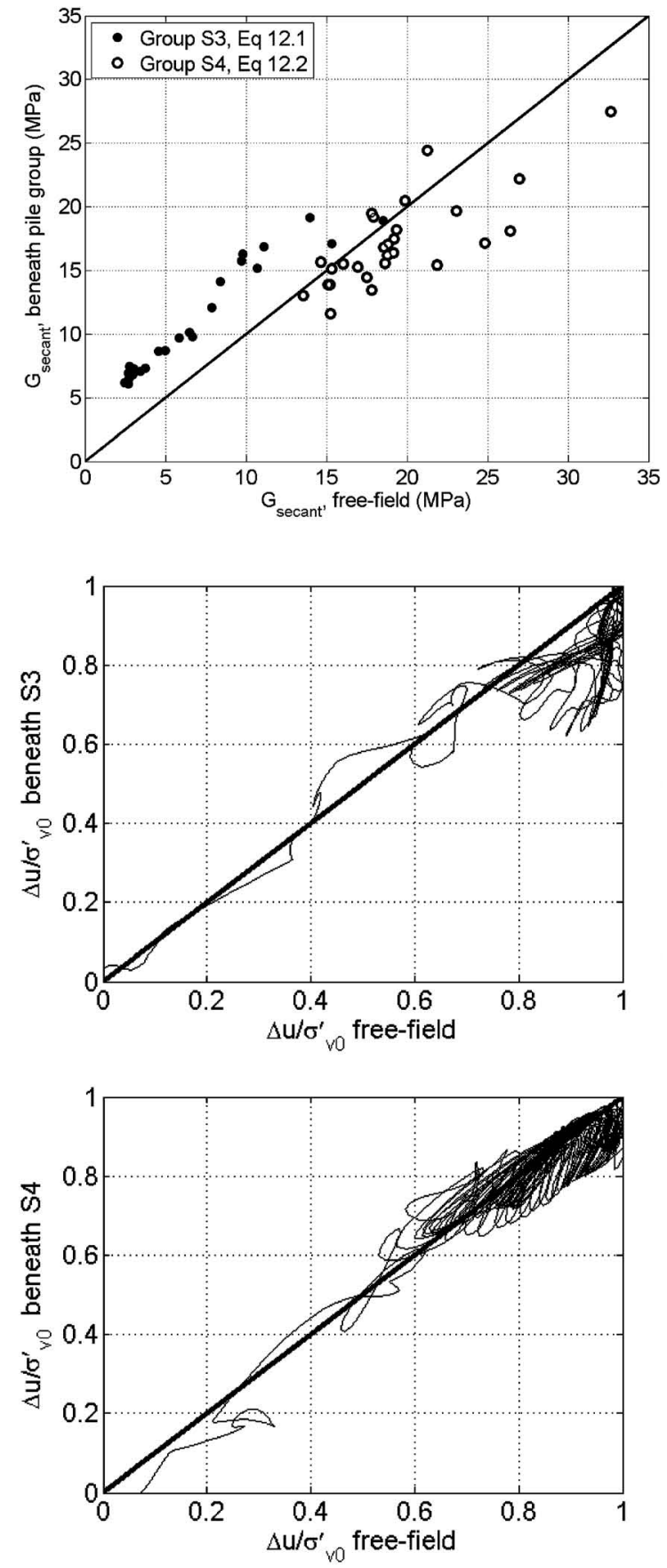

Fig. 9. Comparison of dynamic soil properties local to the pile groups with free-field values

is undrained and the soil therefore incompressible). As the values of $G_{\text {secant }}$ shown in Fig. 9 are average values applicable to whole cycles of shaking, average excess pore pressures (and hence $\sigma_{v}^{\prime}$ ) for each cycle are interpolated from the time-varying measured values. In this way, a pseudostatic prediction of bearing capacity can be obtained, neglecting the more complex dynamic behaviour.

The fit of this model to the measured pile tip loads is shown for one of the instrumented piles in both earthquakes 12.1 (group S3, pile B) and 12.2 (group S4, pile B) in Fig. 10. In estimating post-liquefaction bearing capacity, excess pore pressures measured at pile tip level in the
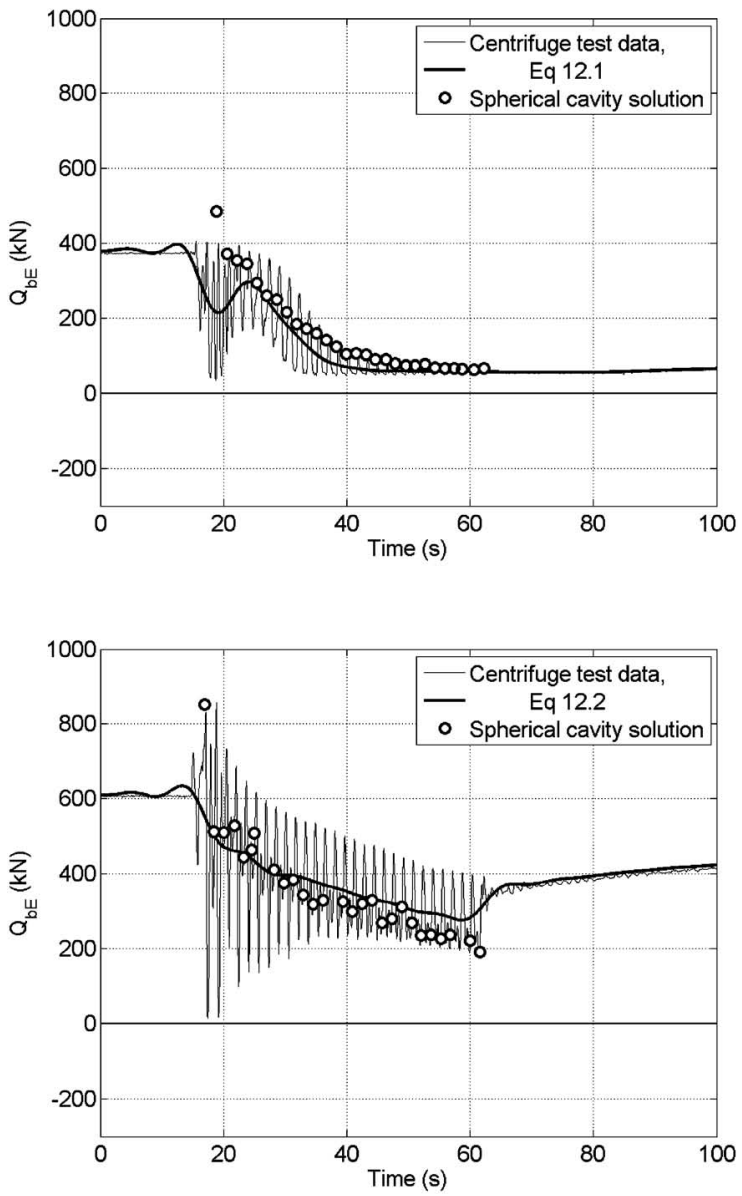

Fig. 10. Comparison of predicted liquefied base capacities with measured base loads

free-field are used along with shear moduli determined mid-way between the tips of the piles and the base of the container ( $\sim 10 D_{0}$ beneath the pile tips) using the method detailed above. The excess pore pressures in the free-field were practically identical to those beneath the measured beneath the pile groups as shown in Fig. 9. This is important as free-field excess pore pressures may be determined from site response analyses. The match between the measured loads and predicted capacities late in the earthquake (after bearing capacity failure has occurred) suggests that bearing capacity reduces as excess pore pressures increase until, when the capacity is less than the initial pile base load $\left(Q_{\mathrm{b} 0}\right)$, the carried load has to reduce to match the lower capacity-the pile simply cannot sustain more load than the instantaneous capacity. The good agreement shown in Fig. 10 is particularly significant for the determination of liquefied bearing capacity in design situations as free field excess pore pressures and shear moduli can be straightforwardly determined using readily available site-response tools such as CYCLIC 1D (http://cyclic.ucsd.edu/; Yang et al., 2003), suggesting that the data from these simple analyses for a given soil profile and earthquake can be used to predict post-liquefaction base capacity. 


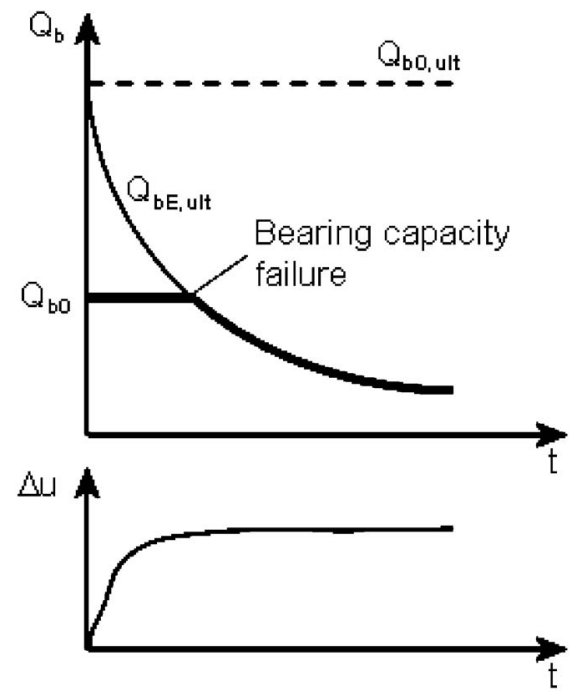

Fig. 11. Theoretical model of bearing capacity failure in liquefying soil

\section{LIMITING SSF FOR LIQUEFIED BEARING CAPACITY FAILURE}

It can be seen from Fig. 6 that the piles investigated in this study are end-bearing piles, carrying significantly more load at the base compared to the shaft under static (initial) conditions. This is a common configuration for piles in liquefaction-susceptible regions in which the piles are driven through soft liquefiable layers to bear in more competent underlying layers. It is reasonable to assume that the pile groups will suffer bearing capacity failure when the post-liquefaction base capacity drops below the initial pile base load, as shown schematically in Fig. 11. This will certainly be a conservative criterion as it was demonstrated in Fig. 5 that both the pile shaft and pile cap can additionally contribute to the bearing capacity as the soil liquefies. Whether bearing capacity failure occurs during earthquake shaking will be dependent both on the degree of liquefaction at the pile tip which governs the capacity, and by the SSF of the pile (which will influence the initial base load carried). Consideration of the form of the bearing capacity solution of Vesic (1972) suggests that the liquefied base capacity can be seen to vary as

$$
q_{\mathrm{bE}, \mathrm{ult}} \propto\left(\sigma_{\mathrm{v}}^{\prime}\right) \frac{3-\sin \phi}{3(1+\sin \phi)} .
$$

This assumes that the variation in the bearing capacity due to the reduction in shear modulus (Figs. 8 and 9) is small compared to the effect of effective stress. This has previously been demonstrated by Knappett and Madabhushi (2008b). The value of $\sigma_{\mathrm{v}}^{\prime}$ at any particular time instant during liquefaction is given by

$$
\sigma_{\mathrm{v}}^{\prime}=\sigma_{\mathrm{v} 0}^{\prime}\left[1-\left(\frac{\Delta u}{\sigma_{\mathrm{v} 0}^{\prime}}\right)\right]
$$

As the ultimate base capacity at $\Delta u / \sigma_{\mathrm{v} 0}^{\prime}=0$ should be equal to the static base capacity $\left(q_{\mathrm{b} 0 \text {,ult }}\right)$, this suggests that

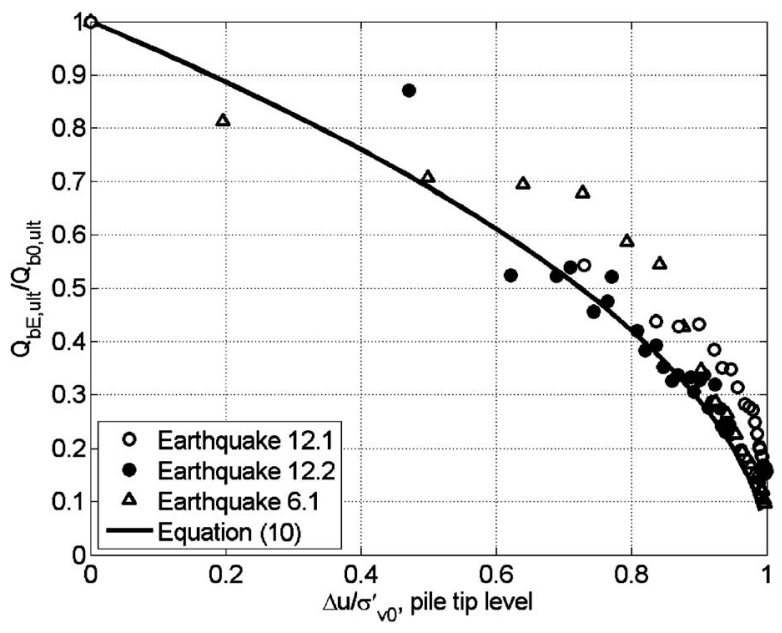

Fig. 12. Reduction in base capacity with increased excess pore pressure

$$
\frac{q_{\mathrm{bE}, \mathrm{ult}}}{q_{\mathrm{b} 0, \mathrm{ult}}}=\frac{Q_{\mathrm{bE}, \mathrm{ult}}}{Q_{\mathrm{b} 0, \mathrm{ult}}}=\left[1-\left(\frac{\Delta u}{\sigma_{\mathrm{v} 0}^{\prime}}\right)\right]^{\frac{3-\sin \phi}{3(1+\sin \phi)}} .
$$

The fit of this expression to the measured data obtained from the centrifuge model tests is shown in Fig. 12. Bearing capacity failure will occur at the tip of the piles when $Q_{\mathrm{bE} \text {,ult }}=Q_{\mathrm{b} 0}$, i.e., when the liquefied base capacity reduces below the initial base load carried under static conditions. The value of $\Delta u / \sigma_{\mathrm{v} 0}^{\prime}$ at which failure occurs can be further related to the SSF of the pile by acknowledging that $Q_{\mathrm{b} 0}$ and $Q_{\mathrm{b} 0 \text {,ult }}$ are related to the total pile load carried and total pile capacity respectively according to

$$
\begin{aligned}
& Q_{\mathrm{b} 0}=\alpha \cdot P \\
& Q_{\mathrm{b} 0, \mathrm{ult}}=\alpha_{\mathrm{ult}} \cdot P_{\mathrm{ult}}
\end{aligned}
$$

in which the values of $\alpha$ and $\alpha_{\text {ult }}$ are indicative of the pile installation conditions (i.e., the degree of pile capacity mobilisation during driving/jacking) and the working loads applied to the pile under static conditions. By substitution of these relationships into Eq. (7), the limiting $\mathrm{SSF}$ for a given amount of excess pore pressure development at the tip of the pile is then given by

$$
\mathrm{SSF}=\left(\frac{\alpha}{\alpha_{\mathrm{ult}}}\right) \frac{1}{\left[1-\left(\frac{\Delta u}{\sigma_{\mathrm{v} 0}^{\prime}}\right)\right]^{\frac{3-\sin \phi}{3(1+\sin \phi)}}} .
$$

The parameter $\alpha$ in Eq. (10) corresponds to the proportion of total pile load $(P)$ prior to shaking (static conditions) which is carried at the base of the pile, while $\alpha_{\text {ult }}$ is similarly the proportion of the ultimate pile capacity $\left(P_{\text {ult }}\right)$ which is provided by the pile base. As $\Delta u / \sigma_{\mathrm{v} 0}^{\prime}$ can be determined for a given earthquake and soil profile using numerical site response programmes (as mentioned previously), Eq. (10) can be used to select a suitable SSF for design purposes to avoid bearing capacity failure during liquefaction.

Equation (10), which represents an ultimate limiting state of pile behaviour, is compared with the limiting SSF 


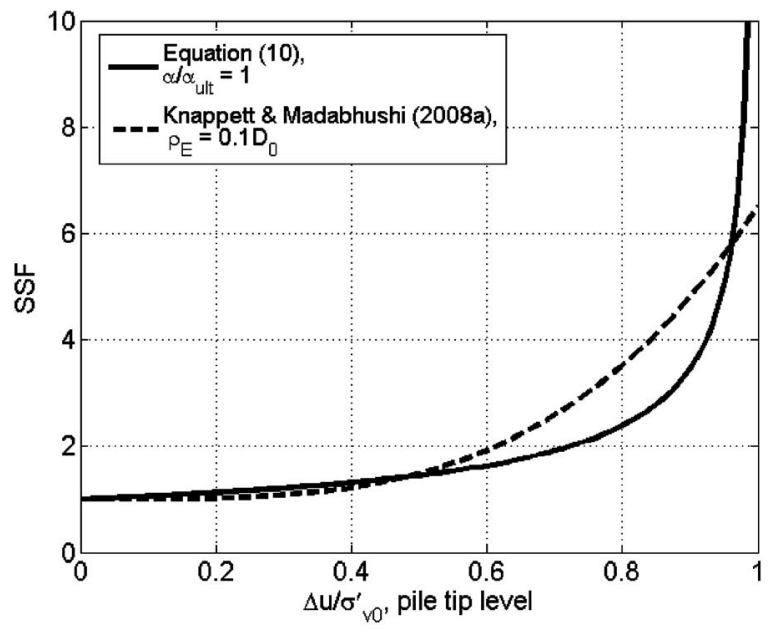

Fig. 13. Comparison of bearing capacity model with limiting displacement model of Knappett and Madabhushi (2008a)

Table 4. Critical excess pore pressure ratios required causing performance criteria to be exceeded

\begin{tabular}{c|c|c}
\hline \multirow{2}{*}{ Criterion } & \multicolumn{2}{|c}{$\Delta u / \sigma_{\mathrm{v} 0}^{\prime}$, pile tip } \\
\cline { 2 - 3 } & $\mathrm{SSF}=2$ & $\mathrm{SSF}=3$ \\
\hline $0.1 D_{0}$ settlement & 0.61 & 0.75 \\
\hline Bearing capacity & 0.72 & 0.87 \\
\hline
\end{tabular}

based on a serviceability-based criterion presented by Knappett and Madabhushi (2008a) in Fig. 13. This was based around determining the limiting SSF such that vertical settlements do not exceed $0.1 D_{0}$ and is described by Eq. (11).

$$
\mathrm{SSF}=1+5.5\left(\frac{\Delta u}{\sigma_{\mathrm{v} 0}^{\prime}}\right)^{3.5}
$$

Equation (11) was determined based on an empirical fit to settlement data obtained from a larger database of centrifuge test data, which includes the two tests described herein. It can be seen that for a given amount of liquefaction $\Delta u / \sigma_{\mathrm{v} 0}^{\prime}$, a slightly larger SSF is generally required if the settlements are to be kept small $\left(<0.1 D_{0}\right)$. Additionally it would suggest that at low excess pore pressures, bearing capacity failure is associated with displacements of approximately $0.1 D_{0}$ while at larger excess pore pressures, the settlement-based limiting state is more demanding than the bearing capacity criteria. For common factors of safety used in static pile design, the degree of excess pore pressure rise at the tip corresponding to meeting one or other of the performance criteria are shown in Table 4. Figure 13 (or alternatively, Eqs. (10) and (11)) may be used in pile design to select suitable static safety factors (and therefore suitable axial loads) for piles founded in liquefiable cohesionless soils.

\section{CONCLUSIONS}

A series of dynamic centrifuge model tests have been presented in which vertical failure and settlement of piled foundations in liquefiable soils has been investigated. Settlements occurring during shaking were found in all cases to be damagingly large (in excess of one pile diameter) which was correlated with an increase in excess pore pressure to full liquefaction conditions in what is conventionally considered to be non-liquefiable soil. Such an increase in excess pore pressure was observed at depths up to $\sim 26 \mathrm{~m}$ in very dense sand, which has important implications for the bearing capacity of long piles. The settlements were also found to be very much larger than downdrag induced settlements induced post-shaking by the reconsolidation of liquefied sand around the piles. Additionally, non-zero pile shaft loads were observed in fully liquefied soil in all tests, contrary to commonly accepted design assumptions. A spherical cavity expansion solution was modified to pseudostatically predict base capacity in liquefying soil. This was found to give excellent agreement with measured loads from the centrifuge tests. Based on these findings, an analytical solution was presented which allows for the determination of a suitable static safety factor in pile design to avoid bearing capacity failure for given liquefaction conditions.

\section{ACKNOWLEDGEMENTS}

The authors would like to sincerely thank the technical staff at the Schofield Centrifuge Centre in Cambridge for their invaluable assistance with the centrifuge testing work. Financial support for the first author and the project was provided by the Engineering and Physical Sciences Research Council (EPSRC) and is acknowledged with thanks.

\section{NOTATION}

\footnotetext{
$A=$ Pile base area

$D_{\mathrm{r}}=$ Relative density

$D_{0}=$ Pile (outside) diameter

$E=$ Young's Modulus

$G\left(\gamma_{\mathrm{s}}\right)=$ Shear modulus

$G_{\text {secant }}=$ Secant shear modulus for a single cycle of shaking

$h_{\mathrm{CM}}=$ Offset between bottom of pile cap and displacement measurement point

$K_{(0)}=$ Coefficient of lateral earth pressure (at rest)

$L_{\mathrm{p}}=$ Pile length

$P=$ Nominal load per pile

$P_{\mathrm{t}}=$ Total superstructural load supported by piled foundation

$P_{\text {ult }}=$ Ultimate static pile capacity

$Q_{\mathrm{bE}}=$ Base load (during earthquake)

$Q_{\mathrm{bE}, \mathrm{ult}}=$ Liquefied (seismic) base capacity $\left(=q_{\mathrm{bE}, \mathrm{ult}} \cdot A\right)$

$q_{\mathrm{bE}, \mathrm{ult}}=$ Liquefied (seismic) base capacity

$Q_{\mathrm{b} 0}=$ Initial base load

$Q_{\mathrm{b} 0 \text {,ult }}=$ Static base capacity (pre-earthquake, $\left.=q_{\mathrm{b} 0 \text {,ult }} \cdot A\right)$

$q_{\mathrm{b} 0 \text {,ult }}=$ Static base capacity (pre-earthquake)

$Q_{\mathrm{sE}}=$ Shaft load (during earthquake)

$Q_{\mathrm{sE} \text {,ult }}=$ Liquefied (seismic) shaft capacity

$Q_{\mathrm{s} 0}=$ Initial shaft load

$Q_{\mathrm{s} 0 \text {,ult }}=$ Static shaft capacity (pre-earthquake)

$\mathrm{SSF}=$ Static safety factor

$\alpha=$ Proportion of total pile load carried at the pile tip $\left(=Q_{\mathrm{b} 0} / P\right)$ $\alpha_{\text {ult }}=$ Proportion of total pile capacity provided by the pile tip (= $\left.Q_{\text {b0,ult }} / P_{\text {ult }}\right)$
} 
$\beta=$ Proportion of total superstructural load supported by piles $\left(=4 P / P_{\mathrm{t}}\right)$

$\gamma_{\mathrm{s}}=$ Soil shear strain

$\Delta_{\mathrm{cyc}}=$ Lateral cyclic displacement of pile cap/pile head

$\Delta u=$ Excess pore pressure

$\phi=$ Critical state soil friction angle

$\mu=$ Coefficient of friction

$v=$ Poisson's ratio

$\rho_{\mathrm{E}}=$ Earthquake-induced settlement

$\rho_{\mathrm{E}, \mathrm{avg}}=$ Average (monotonic) earthquake-induced settlement

$\rho_{\mathrm{E}, \mathrm{cyc}}=$ Cyclic earthquake-induced settlement

$\sigma_{v}^{\prime}=$ Instantaneous vertical effective stress

$\sigma_{\mathrm{v} 0}^{\prime}=$ Initial vertical effective stress

\section{REFERENCES}

1) Berezantzev, V. G., Khristoforov, V. S. and Golubkov, V. N. (1961): Load bearing capacity and deformation of piled foundations, Proc. 5th ICSMFE, Paris, France, 11-15.

2) Boulanger, R. W., Kutter, B. L., Brandenberg, S. J., Singh, P. and Chang, D. (2003): Pile foundations in liquefied and laterally spreading ground during earthquakes: centrifuge experiments and analyses, Report No. UCD/CGM-03/01, University of California, Davis.

3) Brennan, A. J. (2003): Vertical drains as a countermeasure to earthquake-induced soil liquefaction, $P h D$ Thesis, University of Cambridge, UK.

4) Brennan, A. J., Madabhushi, S. P. G. and Houghton, N. E. (2006): Comparing laminar and equivalent shear beam (ESB) containers for dynamic centrifuge modelling, Proc. 6th Int. Conf. on Physical Modelling in Geotechnics '06, Hong Kong, 171-176.

5) Brennan, A. J., Thusyanthan, N. I. and Madabhushi, S. P. G. (2005): Evaluation of shear modulus and damping in dynamic centrifuge tests, Journal of Geotechnical and Geoenvironmental Engineering, 131(12), 1488-1497.

6) Castro, G. (1975): Liquefaction and cyclic mobility of saturated sands, Journal of the Geotechnical Engineering Division, 101(GT6), 551-569.

7) Castro, G. and Poulos, S. J. (1977): Factors affecting liquefaction and cyclic mobility, Journal of the Geotechnical Engineering Division, 103(GT6), 501-516.

8) Cheng, Y. M. (2004): $N_{\mathrm{q}}$ factor for pile foundations by Berezantzev, Geotechnique, 54(2), 149-150.

9) De Alba, P. A. (1983): Pile settlement in liquefying sand deposit, Journal of Geotechnical Engineering, 109(9), 1165-1179.

10) Haldar, S., Sivakumar Babu, G. L. and Bhattacharya, S. (2007) Buckling and bending of slender piles in liquefiable soils during earthquakes: a probabilistic analysis, Design of Foundations in Seismic Areas: Principles and Some Applications.

11) Knappett, J. A. (2006): Piled foundations in liquefiable soils: accounting for axial loads, PhD Thesis, University of Cambridge.

12) Knappett, J. A. and Madabhushi, S. P. G. (2008a): Liquefaction induced settlement of pile groups in liquefied and laterally spreading soils, Journal of Geotechnical and Geoenvironmental Engineering, 134(11), 1609-1618.

13) Knappett, J. A. and Madabhushi, S. P. G. (2008b): Designing against pile-tip bearing capacity failure in liquefiable soil, Proc. BGA 2nd Int. Conf. on Foundations, Dundee, UK, 2, 1237-1246.
14) Kulhawy, F. H. (1984): Limiting tip and side resistance, fact or fallacy, Symposium on Analysis and Design of Pile Foundations, ASCE, San Francisco, 80-98.

15) Lin, S., Tseng, Y., Chiang, C. and Hung, C. L. (2005): Damage of piles caused by lateral spreading-back study of three cases, Seismic Performance and Simulation of Pile Foundations in Liquefied and Laterally Spreading Ground, ASCE Geotechnical Special Publication No. 145, 121-133.

16) Madabhushi, S. P. G. (1994): Effect of pore fluid in dynamic centrifuge modelling, Proc. Centrifuge '94, Balkema, Rotterdam, 127-132.

17) Madabhushi, S. P. G., Schofield, A. N. and Lesley, S. (1998): A new stored angular momentum based earthquake actuator, Proc. Centrifuge '98, Tokyo, Japan, 111-116.

18) Mitchell, R. J. and Dubin, B. I. (1986): Pore pressure generation and dissipation in dense sands under cyclic loading, Canadian Geotechnical Journal, 23(3), 393-398.

19) Rollins, K. M. and Strand, S. R. (2006): Downdrag forces due to liquefaction surrounding a pile, Proc. 8th National Conference on Earthquake Engineering, San Fransisco, CA.

20) Schofield, A. N. (1981): Dynamic and earthquake geotechnical centrifuge modelling, Technical Report CUED/D-SOILS/TR104, University of Cambridge, UK.

21) Steedman, R. S. and Sharp, M. J. (2001): Liquefaction of deep saturated sands under high effective confining stress, Proc. 4th Int. Conf. on Recent Advances in Geotechnical Earthquake Engineering and Soil Dynamics, San Diego, CA, USA, Paper no. SPL1.

22) Stewart, D. P., Chen, Y. R. and Kutter, B. L. (1998): Experience with the use of methylcellulose as a viscous pore fluid in centrifuge models, ASTM Geotechnical Testing Journal, 21(4), 365-369.

23) Tokimatsu, K. and Asaka, Y. (1998): Effects of liquefaction-induced ground displacements on pile performance in the 1995 Hyogoken-Nambu earthquake, Soils and Foundations (Special Issue), 163-177.

24) Tokimatsu, K., Mizuno, H. and Kakurai, M. (1996): Building damage associated with geotechnical problems, Soils and Foundations (Special issue), 219-234.

25) Tokimatsu, K., Oh-Oka, H., Satake, K., Shamoto, Y. and Asaka, Y. (1998): Effects of lateral ground movement on failure patterns of piles in the 1995 Hyogoken-Nambu earthquake, Geotechnical Earthquake Engineering and Soil Dynamics III, ASCE Geotechnical Special Publication No. 75, 1175-1186.

26) Uesugi, M. and Kishida, H. (1986): Frictional resistance at yield between dry sand and mild steel, Soils and Foundations, 26(4), 139-149.

27) Vesic, A. S. (1972): Expansion of cavities in infinite soil mass, Journal of the Soil Mechanics and Foundations Division, 98(SM3), 265-289.

28) Yang, Z., Elgamal, A. and Parra, E. (2003): Computational model for cyclic mobility and associated shear deformation, Journal of Geotechnical and Geoenvironmental Engineering, 129(12), 1119-1127.

29) Yasufuku, N., Ochiai, H. and Ohno, S. (2001): Pile end-bearing capacity of sand related to soil compressibility, Soils and Foundations, 41(4), 59-71.

30) Zhang, L. M. and Ng, A. M. Y. (2005): Probabilistic limiting tolerable displacements for serviceability limit state design of foundations, Geotechnique, 55(2), 151-161. 